\title{
ORIGINAL RESEARCH \\ Pulsed Arterial Spin-Labeled MR Imaging Evaluation of Tuberous Sclerosis
}

J.M. Pollock

C.T. Whitlow

H. Tan

R.A. Kraft

J.H. Burdette

J.A. Maldjian
BACKGROUND AND PURPOSE: Tuberous sclerosis presents with characteristic cortical hamartomas and subependymal nodules associated with seizures. The purpose of this study was to use pulsed arterial spin-labeling (PASL) to quantify the perfusion of the cortical hamartomas and correlate the perfusion values with seizure frequency.

MATERIALS AND METHODS: A retrospective search yielded $16 \mathrm{MR}$ imaging examinations including conventional MR imaging and PASL perfusion performed in 13 patients (age range, 7 months to 23 years) with a history of tuberous sclerosis. The mean perfusion of each cortical hamartoma greater than $5 \mathrm{~mm}$ in size localized with conventional MR imaging sequences was obtained with use of manually drawn regions of interest. Cortical hamartomas were classified as normal, hyperperfused, or hypoperfused on the basis of the mean and SD of the unaffected cortex. Correlation was made between perfusion imaging, conventional imaging, and clinical history

RESULTS: Of the 245 cortical hamartomas, 227 (92.7\%) were hypoperfused, 10 (4.1\%) were hyperperfused, and $8(3.3 \%)$ were unchanged relative to the mean gray matter. One patient had a subependymal giant cell astrocytoma with a mean perfusion of $93.5 \mathrm{~mL} / 100 \mathrm{~g}$ tissue/min. There was a statistically significant positive correlation between seizure frequency and the number of hyperperfused cortical tubers $(r=0.51 ; n=16 ; P=.04)$, with higher seizure frequency associated with a greater number of hyperperfused cortical tubers. There was no significant correlation, however, between seizure frequency and the overall number of cortical tubers $(r=0.20 ; n=16 ; P=.47)$.

CONCLUSIONS: The PASL technique can assess and quantify the perfusion characteristics of a cortical hamartoma. Most lesions are hypoperfused; however, both normally perfused and hyperperfused lesions occur. The presence of hyperperfused cortical tubers was associated with increased seizure frequency.
T uberous sclerosis classically presents with the clinical triad of seizures, adenoma sebaceum, and mental retardation. There are protean imaging manifestations of the disorder including, but not limited to, angiomyolipomas, subependymal nodules, cortical hamartomas, and subependymal giant cell astrocytomas. ${ }^{1}$ Cortical hamartomas are the result of abnormal cellular proliferation. ${ }^{2}$ In rare instances, these lesions may also degenerate into astrocytomas. ${ }^{3-5} \mathrm{MR}$ spectroscopy has shown abnormal metabolites in the cortical tuber thought to be secondary to gliosis or neuronal dysfunction. ${ }^{6-9}$ The spectroscopic findings correlated with the histologic specimens, which showed aberrant synapse formation, enlargement of the gyri, an indistinct gray-white matter border, and astrogliosis. ${ }^{10-12}$ The white matter adjacent to the cortical tubers frequently is abnormal and can have giant cells, hypomyelination, astrogliosis, and neuronal loss. ${ }^{10-12}$ Positron-emission tomography (PET) imaging has shown hypometabolism of

Received August 25, 2008; accepted after revision October 31

From the Departments of Radiology (C.T.W., J.H.B., J.A.M.) and Biomedical Engineering (H.T., R.A.K.), Wake Forest University, Winston-Salem, NC; and Department of Radiology (J.M.P.), Oregon Health and Science University, Portland, Ore.

This work was supported by the Human Brain Project and the National Institute of Biomedical Imaging and Bioengineering through grant EB004673. This work was also partially supported by the Center for Biomolecular Imaging of Wake Forest University School of Medicine, Winston-Salem, NC

Please address correspondence to Jeffrey M. Pollock, MD, Oregon Health and Science University, Department of Radiology, 3181 S.W. Sam Jackson Park Rd, Portland, OR, 97239; e-mail: jeffmpollock@gmail.com

Indicates open access to non-subscribers at www.ajnr.org the pathologic lesions reflecting the inherent neuronal dysfunction of the cortical tuber. ${ }^{13-16}$

Perfusion imaging findings in the cortical hamartomas have not been well described in the literature. ${ }^{16-18}$ Technetium Tc99m hexamethylpropyleneamine oxime single-photon emission CT (SPECT) has revealed hypoperfusion in cortical tubers, and decreased cerebral blood volume has been shown with use of dynamic susceptibility contrast (DSC) MR perfusion techniques. ${ }^{16,17}$ Pulsed arterial spin-labeling (PASL) has several advantages compared with nuclear medicine and DSC techniques in the evaluation of cortical tubers. The perfusion imaging can be performed during the structural MR imaging evaluation. PASL requires no radiation, no intravenous contrast, and no power injection, which may be problematic in young patients. PASL is repeatable in the same session and can quantitate cerebral blood flow (CBF). ${ }^{16,19,20}$

We present the cortical hamartoma perfusion imaging findings in a series of 13 patients evaluated with PASL. We propose that most lesions are hypoperfused; however, a significant percentage of lesions will show normal perfusion or hyperperfusion. An accurate depiction of the perfusion characteristics of the cortical tubers is necessary before using the perfusion findings for localization of the epileptogenic focus.

\section{Materials and Methods}

The PASL technique was performed in 9000 consecutive clinical MR imaging examinations performed on both 1.5 and $3 \mathrm{~T}$ scanners from December 2006 through July 2008. We retrospectively identified those cases of patients with a clinical history of tuberous sclerosis. Patient characteristics, including seizure frequency, cortical hamartoma burden, and conventional imaging findings were correlated 


\begin{tabular}{|c|c|c|c|c|c|c|c|c|c|c|}
\hline \multicolumn{11}{|c|}{ Cortical hamartoma perfusion imaging findings in a series of 13 patients evaluated with pulsed arterial spin-labeling } \\
\hline Pt & $\begin{array}{l}\text { Age } \\
\text { (yr) }\end{array}$ & $\begin{array}{c}\text { Seizures } \\
\text { per } \\
\text { Week }\end{array}$ & $\begin{array}{l}\text { Seizure } \\
\text { Frequency }\end{array}$ & $\begin{array}{l}\text { No. Cortical } \\
\text { Hamartomas } \\
\quad>1 \mathrm{~cm}\end{array}$ & $\begin{array}{c}\text { No. } \\
\text { Hyperperfused } \\
\text { Hamartomas }\end{array}$ & $\begin{array}{c}\text { No. } \\
\text { Hypoperfused } \\
\text { Hamartomas }\end{array}$ & $\begin{array}{l}\text { No. Normally } \\
\text { Perfused } \\
\text { Hamartomas }\end{array}$ & $\begin{array}{l}\text { Mean Normal } \\
\text { GM Perfusion } \\
\text { (mL/100 g/min) }\end{array}$ & $\begin{array}{c}\text { Mean } \\
\text { Hyperperfused } \\
\text { Lesions } \\
\text { (mL/100 g/min) }\end{array}$ & $\begin{array}{c}\text { Mean } \\
\text { Hypoperfused } \\
\text { Lesions } \\
\text { (mL/100 g/min) }\end{array}$ \\
\hline $1 \mathrm{a}$ & 0.7 & 0 & None & 12 & 0 & 11 & 1 & 63.8 & & 26.5 \\
\hline $1 b$ & & & & 12 & 0 & 11 & 1 & 67.9 & & 26.3 \\
\hline $2 a$ & 7 & 0 & None & 10 & 0 & 10 & 0 & 116.6 & & 63.8 \\
\hline $2 b$ & & & & 9 & 0 & 6 & 3 & 123.0 & & 79.8 \\
\hline 3 & 2 & 1 & 1 per week & 21 & 0 & 21 & 0 & 173.6 & & 104.6 \\
\hline $4 a$ & 8 & 2 & $\begin{array}{l}2 \text { per week, left } \\
\text { facial twitch }\end{array}$ & 9 & 3 & 5 & 1 & 108.1 & 155.1 & 68.1 \\
\hline $4 b$ & & & & 9 & 3 & 6 & 0 & 112.4 & 154.0 & 35.3 \\
\hline 5 & 7 & 0 & $\begin{array}{c}\text { None, last } 8 \\
\text { months }\end{array}$ & 3 & 1 & 2 & 0 & 102.3 & 127.7 & 86.7 \\
\hline 6 & 23 & 4 & $\begin{array}{c}4 \text { per week, } \\
\text { EEG left } \\
\text { temporal }\end{array}$ & 23 & 1 & 21 & 1 & 52.8 & 61.4 & 20.0 \\
\hline 7 & 5 & 0 & $\begin{array}{l}\text { None, last } 3 \\
\text { months }\end{array}$ & 41 & 0 & 41 & 0 & 131.4 & & 23.0 \\
\hline 8 & 3 & 3 & 3-4 per week & 18 & 1 & 17 & 0 & 163.2 & 186.7 & 61.6 \\
\hline 9 & 12 & 0 & $\begin{array}{l}\text { None last } 10 \\
\text { years }\end{array}$ & 5 & 0 & 5 & 0 & 85.4 & & 25.6 \\
\hline 10 & 6 & 0 & $\begin{array}{l}\text { None last } 2 \\
\text { years }\end{array}$ & 22 & 1 & 21 & 0 & 122.2 & 151.2 & 45.2 \\
\hline 11 & 3 & 0 & $\begin{array}{c}\text { None last } 3 \\
\text { months }\end{array}$ & 19 & 0 & 18 & 1 & 99.6 & & 38.9 \\
\hline 12 & 10 & 0 & $\begin{array}{c}\text { None last } 3 \\
\text { months }\end{array}$ & 8 & 0 & 8 & 0 & 84.6 & & 22.8 \\
\hline 13 & 11 & 2 & 1-2 per week & 24 & 0 & 24 & 0 & 60.0 & & 23.8 \\
\hline
\end{tabular}

Note:-Pt indicates patient; EEG, electroencephalogram; GM, gray matter.



Patient number

- Average Hypoperfused $\quad=$ Average Grey Matter Perfusion $\quad \equiv$ Average Hyperperfused Lesions

Fig 1. Summary of hamartoma perfusion data for each patient. The average of the hyperperfused lesions is shown in green. The average of the hypoperfused lesions is shown in blue. The mean unaffected gray matter perfusion is shown in red.

with cortical hamartoma perfusion values. Seizure frequency, age, hamartoma burden, average gray matter perfusion, and average hamartoma perfusion values are listed in the accompanying Table. Thirteen patients (mean age, 6.8 years; age range, 7 months to 23 years) were identified with a history of tuberous sclerosis. The mean perfusion values of each patient are summarized in Fig 1. Eight pa- tients had no seizures within the last 3 months. Five patients had 1 to 4 seizures per week.

We generated quantitative CBF maps by using a quantitative imaging of perfusion using a single subtraction with thin-section TI periodic saturation (Q2TIPS) flow-sensitive alternating inversion recovery sequence. ${ }^{21}$ This sequence generates 60 tag and control image 


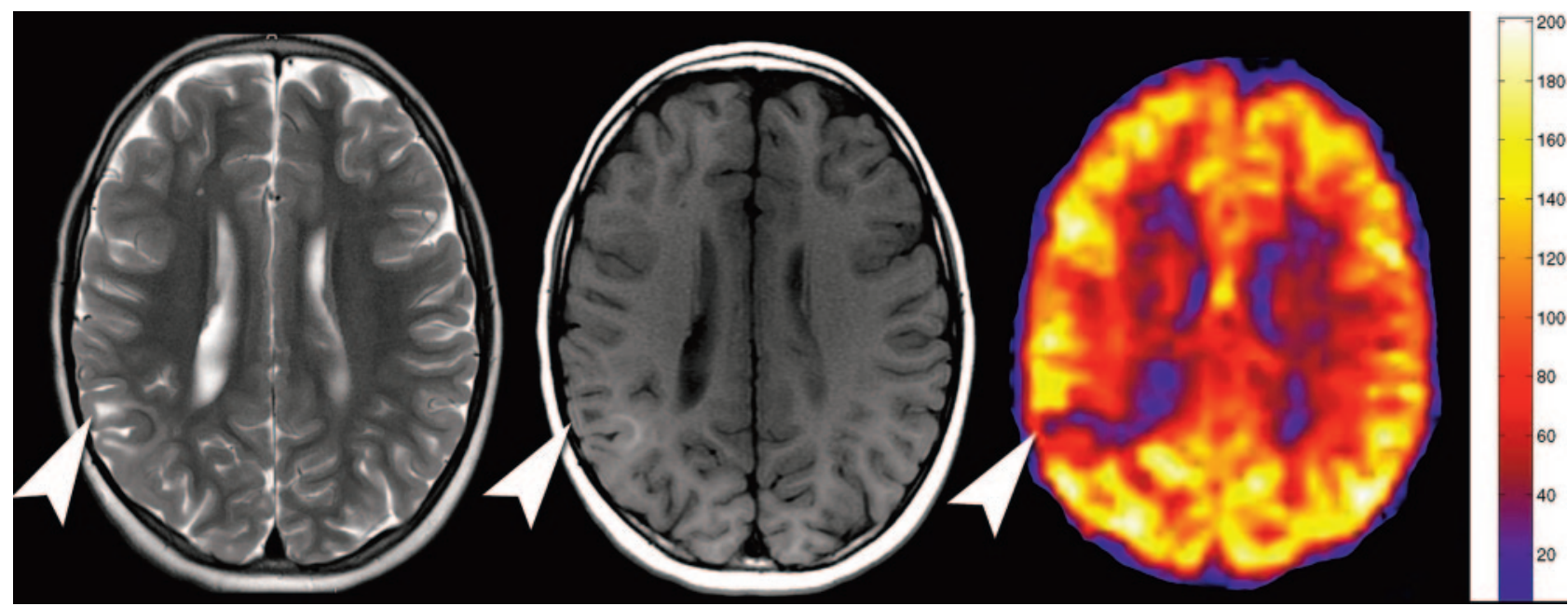

Fig 2. Hypoperfused cortical tuber. Axial T2 (left), axial T1 (center), and quantitative CBF map from the PASL sequence show a cortical tuber (arrowheads) with high T2 signal intensity, mixed T1 signal intensity, and significant hypoperfusion on PASL.

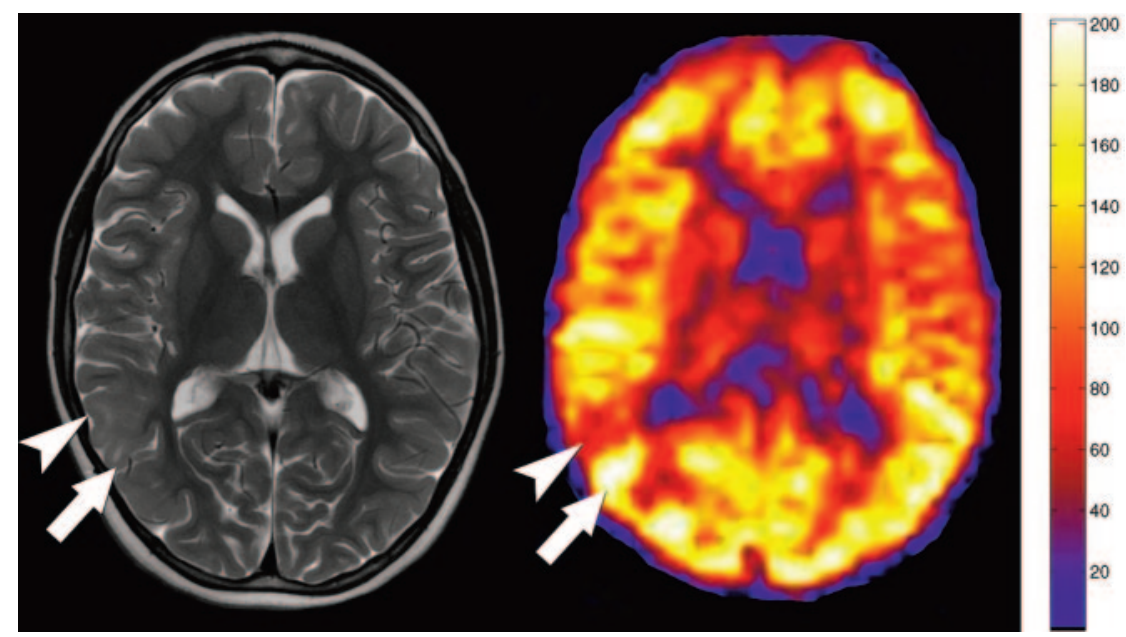

Fig 3. Hyperperfused and hypoperfused cortical tubers. Axial T2-weighted image shows multiple cortical tubers in the right parietal lobe. Additional smaller tubers are seen in the left frontal cortex. Quantitative CBF map from the PASL sequence demonstrates alternating bands of hypoperfusion (arrowhead) and hyperperfusion (arrow) corresponding to the tubers Additional areas of hyperperfusion are seen in the cortex, but these tubers did not meet size criteria to be included in the study.

pairs. Motion correction is applied, and the control and tagged image pairs are then subtracted to generate relative perfusion signal intensity maps. The perfusion maps are segmented according to the anatomic T1-weighted image and then are scaled by the mean signal intensity (M0) of blood. The segmentation and scaling step allows for voxelwise computation of absolute CBF maps. The perfusion maps are colorized with a standard scale, and the JPEG of the resulting image series is sent to the PACS..$^{22,23}$

We localized cortical hamartomas using the conventional T1and T2-weighted sequences. We cross-referenced the gray-scale PASL images to the conventional sequences to draw regions of interest on the PASL sequence corresponding to the cortical signal intensity abnormality. Mean CBF of the region of interest was recorded. As an internal control, the mean and SD of 20 regions of interest of unaffected gray matter (no cortical or adjacent white matter signal intensity abnormality) in the same patient were recorded. Hyperperfused and hypoperfused lesions were defined as perfusion measurements respectively above and below 1 SD from the mean. Normal perfusion was defined as within 1 SD of the mean. Region-of-interest analysis of 1 patient with subependymal giant cell astrocytomas (SEGAs) was also included but was reported separately from the cortical tubers.

\section{Statistical Analysis}

The Pearson correlation coefficient was used to investigate the relationship between seizure frequency and total number of cortical tubers, as well as number of normoperfused, hyperperfused, and hypoperfused cortical tubers. The Pearson correlation coefficient was also used to investigate the relationship between the overall number of cortical tubers and the number of normoperfused, hyperperfused, and hypoperfused cortical tubers. We performed all statistical analyses by using the Statistical Package for the Social Sciences 16.0 (SPSS, Chicago, Ill).

\section{Results}

We identified 245 cortical hamartomas greater than $5 \mathrm{~mm}$ in size in 13 patients: 227 (92.7\%) were hypoperfused (Fig 2), 10 $(4.1 \%)$ were hyperperfused (Fig 3$)$, and $8(3.3 \%)$ were unchanged relative to the mean gray matter. The mean CBF of the hypoperfused hamartomas was $46.9 \mathrm{~mL} / 100 \mathrm{~g}$ tissue/min 


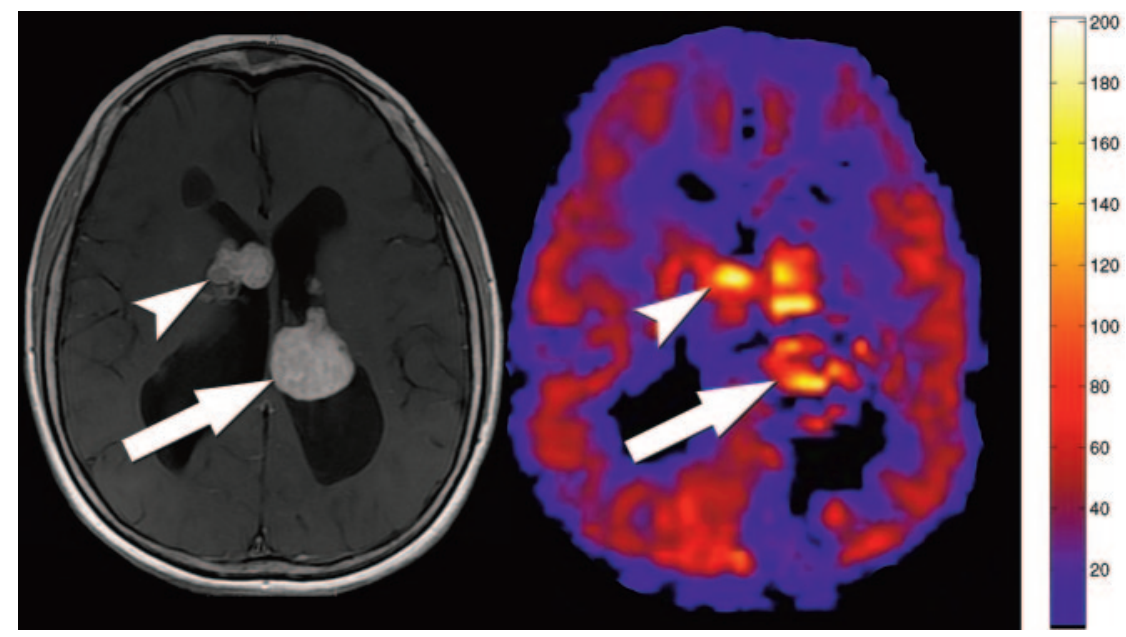

Fig 4. Subependymal giant cell astrocytomas on $T 1$ postcontrast and PASL. Mean perfusion of the lesions was $93.5 \mathrm{~mL} / 100 \mathrm{~g} / \mathrm{min}$. Despite some calcifications in the tumors, the PASL sequence still showed that the lesions (arrow and arrowhead) were significantly hyperperfused relative to mean gray matter. A third lesion is partially seen on the contrasted image at the left foramen of Monroe.

(range, 4.7-147.7 $\mathrm{mL} / 100 \mathrm{~g}$ tissue/min). The mean CBF of the hyperperfused hamartomas was 127.6 (range, $61.4-196.9 \mathrm{~mL} /$ $100 \mathrm{~g}$ tissue/min).

Preliminary analyses were performed to ensure no violation of the assumptions of normality, linearity, and homoscedasticity for the correlation analysis. There was a strong and statistically significant positive correlation between seizure frequency and the number of hyperperfused cortical tubers $(r=0.51 ; n=16 ; P=.04)$, with higher seizure frequency associated with a greater number of hyperperfused cortical tubers. There was no significant correlation, however, between seizure frequency and the overall number of cortical tubers $(r=0.20 ; n=16 ; P=.47)$, number of normoperfused cortical tubers $(r=-.06 ; n=16 ; P=.82)$, or hypoperfused cortical tubers $(r=0.14 ; n=16 ; P=.61)$.

Region-of-interest analysis of the 1 patient with 2 SEGAs showed the mean perfusion values in these lesions to be $93.5 \mathrm{~mL} / 100 \mathrm{~g} / \mathrm{min}$, greater than 2 SDs above the mean unaffected gray matter perfusion of $60 \mathrm{~mL} / 100 \mathrm{~g} / \mathrm{min}$.

\section{Discussion}

Tuberous sclerosis complex (TSC) is an autosomal-dominant disorder with a high spontaneous mutation rate. TSC1 or TSC2 gene mutations, which generate the proteins hamartin and tuberin, result in the clinical manifestations of the disorder. The tumor suppressor protein malfunction causes the variety of disease manifestations on the basis of the expression and distribution of the proteins. ${ }^{24}$ The more severe the tumor suppressor protein malfunction, the more severe the clinical manifestations. ${ }^{25}$ Cortical tuber burden has been correlated with seizure onset and frequency, with mixed results. ${ }^{26-28}$ Our study showed no statistically significant correlation between total cortical tuber count and seizure frequency. The phenotype and mutational analysis of the patients in our study are unknown. The variability in cortical tuber count and symptoms may be related to underlying genetic variability in our series.

Hamartomas have been reported to degenerate into astrocytomas. ${ }^{3-5}$ Two SEGAs had developed in 1 patient. Mean perfusion values in these lesions were significantly increased (mean, $93.5 \mathrm{~mL} / 100 \mathrm{~g} / \mathrm{min}$ ) compared with unaffected gray matter (mean, $60 \mathrm{~mL} / 100 \mathrm{~g} / \mathrm{min}$ ) despite susceptibility artifacts from calcifications in the SEGAs (Fig 4). Given the limited number of SEGAs in our study, the sensitivity and specificity of hyperperfusion in a SEGA remain uncertain and would need a larger study for further evaluation.

In our study, to improve the accuracy by avoiding spurious $\mathrm{CBF}$ measurements given the low signal-to-noise ratio of the PASL sequence, we did not include lesions smaller than $5 \mathrm{~mm}$. The cortex involved with smaller hamartomas had perfusion heterogeneity, but no single cortical hamartoma greater than 5 $\mathrm{mm}$ in size could be localized to the perfusion abnormalities. It is possible that our study underestimated the number of hamartomas because of the size threshold.

Another limitation of PASL was that currently our sequence generates CBF only and does not characterize changes in cerebral blood volume or mean transit time. Dynamic susceptibility contrast has been used to evaluate malformations of cortical development. ${ }^{16}$ Widjaja et $\mathrm{al}^{16}$ found a significant reduction in the hamartoma blood volume but no significant difference in transit time in patients with tuberous sclerosis complex. They also noted that several hamartomas had normal blood volumes. Presumably, lesions in our study were hypoperfused because of decreased blood volume, and those with normal perfusion had normal blood volumes. Widjaja et $\mathrm{al}^{16}$ examined 59 tubers and may not have had enough patients to detect the small population of hyperperfused tubers. We believe the hyperperfused tubers in our study would show increased blood volume, which may be an intrinsic property of the tuber or reflect epileptogenic activity.

Cortical hamartomas can have an indistinct transition from gray to white matter on histologic examination. ${ }^{10,29}$ The PASL sequence relies on gray and white matter segmentation to quantify perfusion values. If segmentation is inaccurate, erroneous perfusion values can be reported. ${ }^{23}$ High-resolution T1-based segmentation maps acquired for all patients were able to accurately distinguish gray and white matter despite the presence of the tubers. The use of the patient with TSC as an internal control group has some theoretic problems. The "unaffected cortex" on imaging may have microscopic 
pathologic changes that cannot be detected with current neuroimaging techniques. ${ }^{30}$ It is unknown whether the microscopic changes can significantly alter local cerebral perfusion. The internal control was selected because of the age-dependent variability in global pediatric cerebral perfusion. ${ }^{31,32}$

Gliosis in the white matter adjacent to the hamartoma has been described previously. ${ }^{30}$ This gliotic white matter may be contributing to the perfusion measurements. It is possible that the regions of interest included small portions of white matter, which could underestimate the perfusion values. Calcifications within a cortical tuber could also artifactually lower PASL perfusion measurements because of the susceptibility effects. ${ }^{23}$ Cortical tubers have been shown to calcify, but this is more characteristic of subependymal nodules. ${ }^{11}$ The patients in this series did not show calcifications or susceptibility artifacts in the selected cortical tubers.

Alternating bands of hyperperfusion and hypoperfusion (Fig 3) have also been seen with nuclear medicine SPECT studies. ${ }^{18,33}$ However, the hyperperfused lesions were identified during the ictal acquisition. The patients in our series did not have clinically apparent seizures during or preceding perfusion imaging. In 1 patient with hyperperfusion, the perfusion pattern was stable at 6-month follow-up. We are uncertain if the patient was having subclinical seizures or if the tubers had baseline hyperperfusion. Although the patient population in our study was small, those patients with hyperperfused cortical tubers did have a statistically significant positive correlation with clinical seizure frequency. However, only 3 of the 5 patients with frequent seizures had hyperperfused tubers, and, in a similar fashion, 3 of the 5 patients with hyperperfused tubers had seizures. This means that although there is a statistically significant association between hyperperfused tubers and seizures, a significant population of patients with seizures will not have hyperperfused tubers. In practical terms, the relationship between hyperperfusion and seizure frequency seems to be an association rather causal. We are uncertain if the identified hyperperfused tubers were the epileptogenic focus. Additional long-term studies with multimodality functional imaging and postsurgical correlation would be necessary to make this determination.

Various methods have been used to localize the epileptogenic cortical tuber in cases of focal intractable epilepsy. These include electroencephalography, PET imaging, ictal SPECT, and magnetoencephalography. ${ }^{13,15,18,33-40}$ Each isolated technique had variable success to correctly identify the problematic cortical tuber. However, the favored approach is to use multiple complementary imaging modalities to accurately and confidently localize the epileptogenic focus before surgical resection. . $^{13,15,18,33-35,37,39-41}$ When seizures can be localized to a single epileptogenic tuber, surgical resection has proved beneficial, with significant reductions in seizure frequency. ${ }^{15,18,33,35-38}$ Future studies with PASL could localize the epileptogenic tuber by establishing the baseline perfusion values of the cortical hamartomas and evaluating the perfusion change associated with the ictal or postictal state similar to nuclear medicine SPECT examinations. ${ }^{18,33}$

\section{Conclusions}

The perfusion characteristics of cortical hamartomas have not been previously evaluated with PASL perfusion imaging. The stratification of lesions into high, low, and normal groups with use of unaffected gray matter as an internal control shows that most lesions are hypoperfused; however, a significant number of lesions are hyperperfused. The presence of hyperperfused cortical hamartomas is associated with an increased frequency of seizure activity. Future studies may incorporate PASL into the seizure algorithm by use of perfusion changes to complement multimodality localization of the epileptogenic hamartoma.

\section{Acknowledgments}

We thank Kathy Pearson for help with computer programming.

\section{References}

1. Sparagana SP, Roach ES. Tuberous sclerosis complex. Curr Opin Neurol 2000;13:115-19

2. Barkovich AJ, Kuzniecky RI, Jackson GD, et al. A developmental and genetic classification for malformations of cortical development. Neurology 2005;65:1873-87

3. Al-Saleem T, Wessner LL, Scheithauer BW, et al. Malignant tumors of the kidney, brain, and soft tissues in children and young adults with the tuberous sclerosis complex. Cancer 1998;83:2208-16

4. Padmalatha C, Harruff RC, Ganick D, et al. Glioblastoma multiforme with tuberous sclerosis. Report of a case. Arch Pathol Lab Med 1980;104:649-50

5. Matsumura $H$, Takimoto $H$, Shimada N, et al. Glioblastoma following radiotherapy in a patient with tuberous sclerosis. Neurol Med Chir (Tokyo) 1998;38:287-91

6. Mukonoweshuro W, Wilkinson ID, Griffiths PD. Proton MR spectroscopy of cortical tubers in adults with tuberous sclerosis complex. AJNR Am J Neuroradiol 2001;22:1920-25

7. Li LM, Cendes F, Bastos AC, et al. Neuronal metabolic dysfunction in patients with cortical developmental malformations: a proton magnetic resonance spectroscopic imaging study. Neurology 1998;50:755-59

8. Matsuo N, Imamura A, Ito R, et al. The correlation between 1H-MR spectroscopy and clinical manifestation with tuberous sclerosis complex. Neuropediatrics 2007;38:126-29

9. Yapici Z, Dortcan N, Baykan BB, et al. Neurological aspects of tuberous sclerosis in relation to MRI/MR spectroscopy findings in children with epilepsy. Neurol Res 2007;29:449-54

10. Trombley IK, Mirra SS. Ultrastructure of tuberous sclerosis: cortical tuber and subependymal tumor. Ann Neurol 1981;9:174-81

11. Bender BL, Yunis EJ. The pathology of tuberous sclerosis. Pathol Annu 1982; 17(Pt 1):339-82

12. Mizuguchi M. Abnormal giant cells in the cerebral lesions of tuberous sclerosis complex. Congenit Anom (Kyoto) 2007;47:2-8

13. Chandra PS, Salamon N, Huang J, et al. FDG-PET/MRI coregistration and diffusion-tensor imaging distinguish epileptogenic tubers and cortex in patients with tuberous sclerosis complex: a preliminary report. Epilepsia 2006;47:1543-49

14. Eluvathingal TJ, Behen ME, Chugani HT, et al. Cerebellar lesions in tuberous sclerosis complex: neurobehavioral and neuroimaging correlates. $J$ Child Neurol 2006;21:846-51

15. Kagawa K, Chugani DC, Asano E, et al. Epilepsy surgery outcome in children with tuberous sclerosis complex evaluated with alpha-[11C]methyl-l-tryptophan positron emission tomography (PET). J Child Neurol 2005;20:429-38

16. Widjaja E, Wilkinson ID, Griffiths PD. Magnetic resonance perfusion imaging in malformations of cortical development. Acta Radiol 2007;48:907-17

17. Sieg KG, Harty JR, Simmons M, et al. Tc-99m HMPAO SPECT imaging of the central nervous system in tuberous sclerosis. Clin Nucl Med 1991;16:665-67

18. Koh S, Jayakar P, Resnick T, et al. The localizing value of ictal SPECT in children with tuberous sclerosis complex and refractory partial epilepsy. Epileptic Disord 1999;1:41-46

19. Warmuth C, Nagel S, Hegemann O, et al. Accuracy of blood flow values determined by arterial spin labeling: a validation study in isolated porcine kidneys. J Magn Reson Imaging 2007;26:353-58

20. Detre JA, Zhang W, Roberts DA, et al. Tissue specific perfusion imaging using arterial spin labeling. NMR Biomed 1994;7:75-82

21. Luh WM, Wong EC, Bandettini PA, et al. QUIPSS II with thin-slice TI1 periodic saturation: a method for improving accuracy of quantitative perfusion imaging using pulsed arterial spin labeling. Magn Reson Med 1999;41:1246-54

22. Maldjian JA, Laurienti PJ, Burdette JH, et al. Clinical implementation of spintag perfusion magnetic resonance imaging. J Comput Assist Tomogr 2008; 32:403-06

23. Deibler AR, Pollock JM, Kraft RA, et al. Arterial spin-labeling in routine clin- 
ical practice, part 1: technique and artifacts. AJNR Am J Neuroradiol 2008;29:1228-34

24. Franz DN. Diagnosis and management of tuberous sclerosis complex. Semin Pediatr Neurol 1998;5:253-68

25. Dabora SL, Jozwiak S, Franz DN, et al. Mutational analysis in a cohort of 224 tuberous sclerosis patients indicates increased severity of TSC2, compared with TSC1, disease in multiple organs. Am J Hum Genet 2001;68:64-80

26. Shepherd CW, Houser OW, Gomez MR. MR findings in tuberous sclerosis complex and correlation with seizure development and mental impairment. AJNR Am J Neuroradiol 1995;16:149-55

27. Goodman M, Lamm SH, Engel A, et al. Cortical tuber count: a biomarker indicating neurologic severity of tuberous sclerosis complex. J Child Neurol 1997;12:85-90

28. Wong V, Khong PL. Tuberous sclerosis complex: correlation of magnetic resonance imaging (MRI) findings with comorbidities. J Child Neurol 2006;21:99-105

29. Nixon JR, Miller GM, Okazaki H, et al. Cerebral tuberous sclerosis: postmortem magnetic resonance imaging and pathologic anatomy. Mayo Clin Proc 1989;64:305-11

30. DiMario FJ Jr. Brain abnormalities in tuberous sclerosis complex. J Child Neurol 2004;19:650-57

31. Wang J, Licht DJ. Pediatric perfusion MR imaging using arterial spin labeling. Neuroimaging Clin N Am 2006;16:149-67, ix.

32. Whitlow CT, Pollock JM, Mussat-Whitlow B, et al. Changes in global rates of cerebral perfusion associated with normal development as measured with MR arterial spin labeling. Annual Meeting of the American Society of Neuroradiology; June 2-5, 2008; New Orleans, La.

33. Koh S, Jayakar P, Dunoyer C, et al. Epilepsy surgery in children with tuberous sclerosis complex: presurgical evaluation and outcome. Epilepsia 2000; 41:1206-13

34. Wu JY, Sutherling WW, Koh S, et al. Magnetic source imaging localizes epileptogenic zone in children with tuberous sclerosis complex. Neurology 2006;66:1270-72

35. Karenfort M, Kruse B, Freitag H, et al. Epilepsy surgery outcome in children with focal epilepsy due to tuberous sclerosis complex. Neuropediatrics 2002;33:255-61

36. Kamimura T, Tohyama J, Oishi M, et al. Magnetoencephalography in patients with tuberous sclerosis and localization-related epilepsy. Epilepsia 2006; 47:991-97

37. Madhavan D, Schaffer S, Yankovsky A, et al. Surgical outcome in tuberous sclerosis complex: a multicenter survey. Epilepsia 2007;48:1625-28

38. Imoto H, Fujii M, Nomura S, et al. [Surgical treatment for intractable epilepsy caused by tuberous sclerosis complex with multiple tubers: case report] No Shinkei Geka 2008;36:155-58

39. Luat AF, Makki M, Chugani HT. Neuroimaging in tuberous sclerosis complex. Curr Opin Neurol 2007;20:142-50

40. Jansen FE, Van Huffelen AC, Van Rijen PC, et al. Epilepsy surgery in tuberous sclerosis: the Dutch experience. Seizure 2007;16:445-53

41. Jansen FE, van Huffelen AC, Algra A, et al. Epilepsy surgery in tuberous sclerosis: a systematic review. Epilepsia 2007;48:1477-84 